\title{
Learning to look from different perspectives - what can dental undergraduates learn from an arts and humanities-based teaching approach?
}

\author{
F. Smyth Zahra*1 and K. Dunton²
}

\section{In brief}

Emphasises the need in clinical education to educate for capabilities and tolerance of ambiguity.
Describes an innovative pilot project that explores aspects of arts and humanities-based teaching and learning in dental undergraduate education.
Highlights the importance of cross-faculty interprofessional education and collaboration between arts, humanities and the clinical sciences.

By its nature, clinical teaching involves supporting small groups of dental students at the chairside as they treat their own patients. Scaffolding their learning in this way enables observation at close quarters of the various stages of development from early novice, just commencing clinical treatment of patients, to those approaching qualification. The students' main concerns throughout are not primarily with the technical skills required, which they have already been taught in the clinical skills laboratories, but dealing with the complex realities and ambiguities of clinical practice; the 'hidden curriculum' of decision making, judgement calls, issues of communication and what it actually means to be professional. Yet, in an already packed curriculum little time is spent helping the students develop these higher order skills. In an effort to improve clinical reasoning and interpretative skills, many medical schools in the US and a number of leading medical schools here in the UK now incorporate arts and humanities-based initiatives into their curricula. This allows for a greater balance between the objectivity of evidence-based medicine and the pluralism and subjectivity of the arts and humanities, providing a more holistic, patient-centred education that promotes a tolerance of ambiguity. In this paper, we describe a pilot programme which sought to explore the value of this approach in the context of dental education, and share early indicators that balancing interventions of this type with clinical sciences can enhance dental students' capabilities in their professional and personal development. We conclude that in today's complex world we must educate not just for competence, but for capability and that the interdisciplinarity afforded by the 'clinical humanities' is both a promising area for further educational research and potentially a valuable addition to the curriculum.

\section{Introduction}

The academic disciplines of the arts and humanities, steeped in subjectivity and interpretation, teach critical analysis, promote the contesting of ideas and foster creativity. Above all, they seek to enlighten our understanding of the human condition. The benefit of an arts and humanities education for understanding the complexities

${ }^{1}$ Clinical Teacher, Periodontology Department and PG student KLI MACE programme, King's College London Dental Institute, Guy's Hospital, Great Maze Pond London, SE1 9RT; ${ }^{2}$ Research and Education Manager, Cultural Institute King's College London, Room1, 12 Somerset House, East Wing, Strand, London, WC2R 1LA

${ }^{*}$ Correspondence to: Flora Smyth Zahra

Email: flora.smyth_zahra@kcl.ac.uk

Refereed Paper. Accepted 3 January 2016

DOI: 10.1038/sj.bdj.2017.109

${ }^{\circ}$ British Dental Journal 2017; 222: 147-150 of real life was recognised as early as the fourth century by Aristotle who asserted that the ability of drama to imitate the actions of men, based on good and bad moral decisions, allows us to step outside of our own egocentricity and gain insight into the general lot of humanity. Hundreds of years later, John Dewey argued that not only were clinicians in a unique environment to integrate science and the humanities, but that school curricula should mirror real life and, 'If education is life, all life has, from the outset, a scientific aspect, an aspect of art and culture, and an aspect of communication.' ${ }^{1}$ But it is the Carnegie reports of 1910 and 2010 that have had the greatest influence on clinical education. ${ }^{2}$ In the first report, Albert Flexner called for a balance between 'humanity and empiricism'. He assumed that medical students would have already been educated in the humanities and that they 'should be culturally experienced' before joining medical school. ${ }^{3} \mathrm{His}$ emphasis, therefore, was on the study of clinical sciences within teaching hospitals which has largely prevailed since. In 1983 Donald Schon 'challenged practitioners to reconsider the role of technical knowledge versus artistry in the development of professional excellence. ${ }^{4}$ More recently Roger Kneebone of Imperial College has argued for a more even balance between the humanities and medical education in order to help address the complex decision making of clinical practice. ${ }^{5}$ This view is supported by others who argue that the humanities offer much in developing professional and humanistic skills in medical education. ${ }^{6}$ At the beginning of the present century the rapid increase in biomedical research, the fast pace of change and the complexities of delivery of care to patients led 
the 2010 Carnegie report to call for curriculum change, insisting that clinical education become more learner focused, and experiential, and to integrate the clinical with social sciences and humanities to develop professional values and inculcate students to take a 'holistic view of patient experience.' Throughout the US and UK more medical schools are incorporating aspects of arts and humanities programmes into their curricula and recognising their value. ${ }^{7}$ The task of evaluating the impact of humanities programmes within medicine is not without its difficulties, as will be discussed below, however, an evidence base for its effectiveness is gradually emerging. Katz (2014) $)^{8}$ and Gaufberg (2008) ${ }^{9}$ have individually shown that this approach to learning may improve medical students' resilience, communication and clinical observations and also go some way to addressing 'the hidden curriculum' within the community of practice. More targeted interventions have also been undertaken. One study, for example, describes an arts intervention to teach visual observation skills to an interprofessional group of medical and nursing students which led to improved communication skills and tolerance to ambiguity. ${ }^{10}$ Another study uses qualitative thematic analysis to evaluate a short medical humanities student selected module, finding that higher levels of reflection were promoted. ${ }^{11}$ Since dental students face the same pressures and steep learning curve as medical students as they go from the classroom to clinic, there is no reason why arts and humanities-based learning shouldn't have the same potential to enhance not only their clinical skills and student experience but also their ability to care for patients and themselves.

\section{Research methods}

To explore this in practice a pilot was developed between the Cultural Institute and Dental Institute at King's College London that might support students to participate and reflect on the many processes involved in the acquisition of professional mastery including haptic and other sensory skills, as well as the ability to negotiate the complex layers of interpreting, judging and communication that take place within the clinical encounter. The programme also aimed to provide a supportive and trusting space where the ambiguities and uncertainties experienced by students in the clinical setting could be held and explored in a constructive way. With this in mind, two key decisions were made. The first was to blend elements of medical humanities with what GP Louise Younie has termed 'arts-based inquiry,' ${ }^{12}$ that is to say, students would both discuss existing artworks and actively engage in making, writing and performing as part of a reflective and experiential learning programme. The second decision was that each session in the programme would be developed through close collaboration between the clinical academic lead and a carefully chosen expert in the arts and humanities, ensuring that a genuine dialogue between the two fields was established and direct clinical relevance was maintained throughout: an approach that, following Shapiro, we called clinical humanities, that is to say 'the study of the humanities that is strongly linked to praxis.'

A voluntary, extra-curricular programme was developed that would offer six sessions over six consecutive weeks in the evening after clinics. This would allow time for a range of approaches to be tried and good group cohesion to develop while fitting in around the students' schedule. It was also agreed that students would receive a certificate of participation to add to their experience portfolio as part of their 'Higher Education Achievement Record, which aims to highlight all aspects of their undergraduate attainments, both curricular and extra-curricular. The pilot targeted students under the age of 23 without a previous university degree. This was in response to previous work carried out on the reflective habits of students at the Dental Institute at KCL which indicated that students in this category could benefit more from tutoring in reflective thinking. ${ }^{13}$ Thus, 3BDS students of $<23$ years old, without a previous university degree, were invited to participate, and 20 students were randomly recruited from those who responded.

Ethics approval was given to analyse in detail the experiences of the students through a range of means, including weekly written reflections, video footage, student responses to open questions, and feedback on what they perceived to have been the effect of this type of intervention. Permission was also obtained to access the students' end of year OSCE exam results and to follow the students' progress through their remaining years at the Dental Institute.

Since clinical humanities remains a fairly uncharted field of exploration within education, it was not possible, nor indeed appropriate, to start with a set of traditional learning outcomes against which the success of the pilot would be measured. Rather we began with a direction of travel, designing an intervention that we felt might develop students' reflections on professional identity and artistry while remaining open to the fact that any change that the intervention might make within the context of the student experience would only fully emerge retrospectively. To ensure that our retrospective analysis was robust, we opted for an 'illuminative evaluation. This method, 'rooted in social anthropology $^{14}$ was originally employed to evaluate small educational programmes in the context of the learning milieu'14 where it was recommended to observe and interview participants and record fairly open ended data, followed by a more focused phase exploring issues as they arose in greater detail, before, finally, looking for themes and patterns. In this approach, the importance is in the detail of qualitative, data but this does not exclude any quantitative data generated. In the context of the intervention described here, the strength of this methodology was the potential richness of the data generated, from which theories could emerge and openly and flexibly 'illuminate' the intervention. It was important, therefore, that the methods for gathering data, for example, video-ethnography, tutor observations, student reflections, (described in more detail below), were designed into the pilot programme from the outset.

\section{The sessions}

The first session was an attempt to place dentistry in its historical and social context, taking advantage of our close proximity to the Old Operating Theatre and Herb Garret in St Thomas' Street. Through a walking tour of the area and a visit to the museum, students were invited to consider: What is patient-centred care and what skills are involved in delivering it? What kind of dentist do I want to be? Where do I fit into the world of my university and the dental team? What are my values? What does studying as a humanities student entail and does this have relevance to me as a dental student?

For the second meeting, in our capacities as Art Historian and Clinical Teacher of Dentistry, we ran a joint session at the Courtauld Institute which neighbours the King's College Strand Campus. This focused on close visual observation and used questioning sequences to sustain the students' attention - we looked at just two paintings for forty minutes each. Students were invited to use the visual evidence presented by the artworks, with just a few supporting materials, to uncover a range of overt and 
hidden meanings for themselves. Throughout the session, students were prompted to reflect on parallels with the dental examination, smile aesthetics, symmetry, golden ratio, the balance of tones and textures, and the ambiguities faced in clinical practice.

Session three involved a practical workshop and role-play with a professional actor and dealt with good communication techniques, non-verbal communication, good listening and whether histories should be taken or received.

At our fourth session, led by a professional screenwriter and $\mathrm{PhD}$ film-studies student at King's, students used film clips and a short screenwriting activity to consider complex decision-making, ambiguity, making judgement calls and patients as people.

At the fifth session the students thought about ceramics from a different perspective, exploring aesthetic ambiguity with Tamsin van Essen, an internationally respected ceramicist who has collaborated previously with the School of Anatomy at KCL. Through Tamsin's work and then working with ceramic clay themselves, students considered 'feeling the unseen' in dentistry, proprioception, and erosion, attrition and abrasion effects on ceramic clay.

The final session was led by Professor Roger Kneebone, a Wellcome Engagement Fellow who established and leads the UK's only Masters in Surgical Education at Imperial College. Roger discussed how his many collaborations with puppeteers, artists, tailors and crafts people allow him to view surgery from different perspectives and shared his interests in the relationships between the clinical sciences, the craft of surgery and the humanities.

\section{Evaluation}

Evaluation of art interventions in clinical education is challenging precisely because it sits 'at a crossroads of contrasting cultural values and epistemological frameworks. ${ }^{15}$ Given 'the evidence hierarchy in medical discourse ${ }^{15}$ an ideal evaluation needs, on the one hand, to be robust enough to satisfy the faculty who are mostly clinicians and therefore tend to instinctively place a higher value on the quantitative research criteria they themselves are more familiar with, and on the other, be able to capture via qualitative research the depth, nuances and character of innovative cultural interventions.
Through triangulation of the data it is hoped to capture the different dimensions of the phenomenon and increase the validity of the research. Feedback through written reflections, video footage and focus groups is currently being subjected to thematic analysis and evaluated as part of a Master's dissertation. The results will be published in a follow-up paper; however it is known that to date the pilot cohort showed a $4 \%$ higher overall OSCE score than their peers in their summer exams and their feedback indicates that the experience has been extremely positive as indicated in the many pages of reflection produced. To give just a few examples:

'Medicine and dentistry are not hard, exact sciences, and the clinician's scientific expertise is often not enough to solve a patient's particular problem. The patient and clinician must work together to bridge the gaps of knowledge when certain aspects do not appear textbook. This is one of the aspects of visiting the Old Operating Theatre that I found the most fascinating.'

'It was definitely interesting to note how similar art is to dentistry; we often have to analyse our own work, articles, textbooks, journals and so on and this was something that very much translated into what we were doing while discussing the artwork today. Though perhaps we did this more thoroughly in that we were looking for meaning from the painting, the analytical skills we used were the same as those we use in dentistry.'

'I really think the actor's advice was helpful, especially at this point in our course where we have just started to see patients and are quickly having to learn how to read situations that can be quite stressful and deal with patients that are nervous and don't always have the best time coming to see the dentist. It also taught us how to deal with stressful and daunting exam situations such as our upcoming OSCEs and the role-playing helped to show us where little things such as how you rest your hands, which may be very subtle, can change how the patient may interact with you.'

'The workshop proved to be a lot more than just a workshop. The actor took the time to go through some of the techniques he has learnt through Drama school. He had some really useful pointers on how to be professional, still approachable when with patients and also the importance of being able to separate your different 'personas' for example being 'professional' at work and then going home and relaxing, leaving the stresses of the day behind.'

'I loved the ceramics session and found it really interesting and useful. I had never thought of using arts and humanities as part of dentistry before but now I want to integrate this as part of my learning experience.'

Looking across the written reflections as a whole, and drawing also on the many informal conversations that took place with students during the pilot, it is interesting to note how the students began to develop a language to reflect on their professional identity, articulate the skills that they have already developed, and consider what it means to be simultaneously a learner and a practicing clinician. They were able to discuss the complexities and ambiguities of real-life clinical encounters, express some of the anxieties that this gives rise to, and identify the range of decisions and thought processes that come into play when dealing with these situations. Students also expressed their surprise at how much they had enjoyed engaging with art works and activities for their own sake, adding a further, and highly positive, dimension to their experience at King's.

\section{Conclusion}

The intersection between science and the arts and humanities has been fundamental to periods of great innovation throughout history from the Golden age of Islamic culture, the Renaissance and now in the twenty-first century. Over the next ten to twenty years the use of both haptics technology and simulation will become more mainstream in dental education in line with current trends in surgical education. Modern dental practice with its increasing array of diagnostic tools, treatment modalities and increased patient expectation is becoming ever more complex. Poor judgement, inadequate record keeping, poor communication, lack of professionalism and unethical practice constitute the majority of fitness to practice cases against dentists by the UK regulator. ${ }^{16}$ It is therefore even more important to address the 'hidden curriculum,' the ambiguity of practice, complex decision making, judgement calls, communication and professionalism and balance the scientific advances with improved analytical, observational, reflective, and patient-centred skills.

The pilot described here introduced some of the youngest dental students at KCL Dental Institute, most of whom had studied entirely maths and science subjects for A level, to aspects of arts and humanities teaching and learning in order to view clinical practice from a different perspective and help in their professional development. As the evaluation is undertaken, it is becoming clear that by 
introducing the students to the intersections of arts, humanities and the clinical sciences 'the phenomenon of the Medici effect, ${ }^{37}$ has occurred. The students' capacity for written reflection has dramatically increased, some are writing poetry, others innovating in aspects of dental public health and others still have become international award winning film makers. Looking at dentistry from these different perspectives has shown the students that technical knowledge is only a very small part of what constitutes a clinician and the course has developed their capacity for associated learning. ${ }^{18}$ The small group experiential learning seemed to provide the safe space necessary for discussion, analysis, evaluation and creative thinking. The subjectivity of arts and humanities, close observation and group reading of texts, intent listening and openly addressing ambiguity and uncertainty appears to have empowered the students. It would seem, therefore, so far, that the affordance of the clinical humanities in dentistry is in promoting higher order skills, helping students to look beyond their loupes, furthering their professional development and improving their ability to deal with the ambiguities and complex decision-making of clinical practice, while at the same time nurturing their capacity to be the leaders and innovators of the future enabling them to take on the challenges of the next hundred years.

We conclude that the integration of the humanities, art, craft and science in dental education can only further student learning; developing their professional mastery and artistry and ultimately improving patient care.

1. Dewey J. Experience and Education. New York: Simon and Schuster, 1938

2. Irby D. Cooke, M, O'Brien B C. Calls for reform of Medica Education by the Carnegie Foundation for the Advancement of Teaching: 1910 and 2010. Acad Med 2010; 85: 220-227.

3. Flexner A. Medical education: A comparative study. New York: Macmillan, 1925

4. Schon, D. The Reflective Practitioner. How Professionals think in action. New York. Basic books, 1984.

5. Kneebone R. Total Internal reflection. Med Educ 2002; 36: 514-518.

6. Shapiro J, Coulehan J, Wear D, Montello M. Medical Humanities and their Discontents: Definitions, Critiques and Implications. Acad Med 2009; 84: 192-198.
7. Charon R. Narrative Medicine A Model for Empathy, Reflec tion, Profession, and Trust JAMA 2001; 286: 1897-1902.

8. Katz J. Can visual arts training improve physician performance? Trans Am Clin Climatol Assoc 2014; 125: 331-342.

9. Gaufberg E. Teaching and Learning Moments: Learning to Listen. Acad Med 2008; 83: 389.

10. Klugman C, Peel J, Beckmann-Mendez D. Art rounds: teaching interprofessional students visual thinking strategies at one school. Acad Med 2011; 86: 1266-1271.

11. Patterson A. Sharek D, Hennessy M, Phillips M, Schofield S. Medical Humanities: a closer look. Med Hum 2016; DOI:10.1136/medhum-2015-010834.

12. Younie, Louise. Introducing Arts-Based Inquiry into Medical Education. 'Exploring the Creative Arts in Health and IIIness'. In McIntosh P (ed) Creativity in the Classroom. Intellect Books: Bristol, 2013.

13. Tricio J, Woolford M, Escudier M. Dental Students' reflective habits: Is there a relation with their academic achievements? EurJ Dent Educ 2015; 19: 113-121.

14. Parlett M. Hamilton D. Occasional Paper 9 'Evaluation as Illumination: A New Approach to the Study of Innovatory Programs. Centre for Research in the Educational Sciences, University of Edinburgh, Edinburgh, 1972.

15. Rooke A. Arts and Mental Health: Creative collisions and critical conversations. London Arts Humanities Research Council, 2014.

16. GDC. Considerations. 2015. Available online at http:// www.gdc-uk.org/Dentalprofessionals/Fitnesstopractise/ Documents/2015-04-09_Considerations\%202014\%20 -\%20report.pdf (accessed January 2017).

17. Johansson F. The Medici effect. What elephants and epidemics can teach us about innovation. HBR Books: Boston, 2006.

18. Dyer J, Gregersen H, Christensen C. The Innovator's DNA. HBR Press: Boston, 2011 